\title{
MONOAMINE OXIDASE INHIBITORS: CLINICAL PROFILE OF RESPONDERS
}

\author{
M. K. Hasan, M.D., F.R.C.P. (C), M.R.C. Psych. (U.K.), D.P.M. (London)* \\ Roger P. Mooney, M.A.+
}

\begin{abstract}
The authors present three case histories illustrating the effective use of monoamine oxidase inhibitors in the treatment of atypical depression. The characteristics of those individuals who typically respond to the monoamine oxidase inhibitors are described and recommendations for treatment are given.

Although monoamine oxidase inhibitors (MAOI) have been in existence for the past 20 years, their use remains controversial, especially in U.S.A. where fear of adverse reactions with practice of defensive medicine precludes its use. Recent studies in U.K. and Canada have shown that patients with phobic anxiety, atypical depression, panic attacks, and phobias do respond well to MAOI treatment if used in appropriate dosages (e.g., phenelzine 60 $\mathrm{mg}$ (day).

The following three case histories illustrate the type of patients who are likely to respond to MAOI.

\section{Case One}

M. S., a 49-year-old happily married female of 30 years, was diagnosed as a manic-depressive. M. S.

Tricyclics were then added to lithium she was on. The dose of amitriptyline was increased to $250 \mathrm{mg}$ per day with no success. Her complaints persisted. This was switched to imipramine (up to $300 \mathrm{mg}$ ) with no change in her condition. As symptoms of weakness and tiredness persisted, tricyclics were discontinued. After a 10-day washout period, Parnate $10 \mathrm{mg}$. b.i.d. was added to lithium and was subsequently increased to $30 \mathrm{mg} /$ day over a period of 10 days. She improved, returning to her "normal self' in six weeks. She has continued to do well for the past 12 months and has been maintained on Parnate $10 \mathrm{mg}$ b.i.d. and lithium carbonate $300 \mathrm{mg}$ t.i.d. She has resumed teaching, gives piano lessons, and according to her husband, is "back to her old self."
\end{abstract} had done relatively well for two years on lithium; however, depressive episodes occurred despite adequate lithium levels. No obvious precipitating factor, either at home or family situation, was noted. She became extremely depressed and at times suicidal. Her complaints were, "I am not my usual self," and "I feel weak and I have no pep... I can't live like this."

Family history was uneventful apart from her being, in her own words, 'demanding and getting my way" as a child. The husband described her as an "assertive, pushy woman... obsessional and meticulous... always jolly..." and always wanting to be the "center of attraction in a group."

-Psychiatrist, Division of Behavioral Sciences \& Psychiatry, Beckley Appalachian Regional Hospital, 306 Stanaford Road, Beckley, West Virginia 25801; Assistant Clinical Professor, Department of Psychiatry, Marshall University School of Medicine, Huntington, West Virginia 25701.

+ Clinical Psychologist, Division of Behavioral Sciences \& Psychiatry, Beckley Appalachian Regional Hospital, 306 Stanaford Road, Beckley,

West Virginia 25801.

\section{Case Two}

J. R., a 32-year-old, attractive, happily married female was seen in the office with a history of chronic depression off and on for 10 years. Lately, however, "Life has become unbearable." The depression persisted with short periods of remission. She was anxious and had a number of psychosomatic compłaints, stating, "I am scared, I don't know why." A predominant feeling of fear was present and she expressed "a feeling of impending doom." To quote her, "I feel something is going to happen." The husband, a well-known socialite, became increasingly worried about the wife's isolationism. She has also been taking large quantities of minor tranquilizers, e.g., Valium (up to $40 \mathrm{mg}$ per day). The husband described her as "fastidious, picky, and difficult to live with."

Family history was uneventful except for her "always wanting to be the center of attraction." When she was 15 years old, she had a grand mal seizure, with detrimental effects on self-image. She was treated with Dilantin for three years and has remained seizure free since then. She was admitted to the hospital and was weaned off Valium over a three-week period. Three days after the Valium was discontinued, she had a grand mal seizure. An EEG 
was done soon after the seizure and showed an epileptic focus in the temporal region. The possibility of a withdrawal seizure was raised, but the presence of an epileptic focus and an additional seizure two days later, necessitated the diagnosis of a seizure disorder. Dilantin $200 \mathrm{mg} /$ day was started. As the seizures were controlled and she felt better, she was discharged to be seen on an outpatient basis. Two weeks later, her symptoms of anxiety, panic attacks, and depression returned. Parnate $10 \mathrm{mg} /$ day was added and increased to $10 \mathrm{mg}$ b.i.d. after 5 days. She improved slowly. The feelings of fear and panic decreased and the depression improved over a four-week period. Behavior therapy with the help of a cooperative husband was initiated. She improved gradually and subsequently returned to work. Currently she is doing well on Parnate10 mg b.i.d., Dilantin200 mg@hs and supportive psychotherapy on an outpatient basis. She has returned to her "normal self" after a long time, according to the patient and her husband.

\section{Case Three}

B. S., a 42-year old divorced white male was admitted to our unit with a history of drinking for the past several years, becoming worse since his divorce five years prior to admission, this being his fifth admission. He was one of eight siblings, describing himself as the "black sheep of the family." "I was full of energy and ran around a lot." While working as Assistant Supervisor in the mines, he started to get depressed, finding the responsibilities overwhelming. A faltering marriage of 17 years ended in divorce, thus compounding the picture. He started to experience bouts of depression associated with feelings of "impending doom" and panic. Alcohol relieved the inner tension. He continued to work, but "continued to remain chronically anxious and depressed with a panicky feeling all the time." $\mathrm{He}$ was hospitalized in a private hospital for six weeks, receiving tricyclic antidepressants and psychotherapy with little relief.

Treatment at the local mental health center was unsuccessful. He subsequently lost his job because of periodic absenteeism. He was hospitalized on our unit on four different occasions for alcoholism and depression. Various tricyclics in large doses, Antabuse, individual and group therapy, and Alcoholics Anonymous were initiated on each occasion with little result. He remained sober for less than a month.

His usual complaints following detoxification were, "I don't feel well ... I I feel weak and I have no pep.... I feel scared ... something is going to happen." He scored 14 on the Beck Depression Scale. The MMPI showed high scores on neuroticism depression and obsessionality. The man described himself as a perfectionist. Further history revealed that he had now developed a fear of crowded places and social situations with increasing tension and inability to relax even for short periods. A diagnosis of phobic panic attacks with depression was made and he was started on MAOI (Nardil 15 mg b.i.d., increased to $30 \mathrm{mg}$ b.i.d. after two weeks). Some improvement was noticed and in three weeks, for the first time, he started to feel, inhis words, like "my normal self." Nardil served as an antidepressant and required abstinence from alcohol - a dual purpose. Supportive psychotherapy was continued, including help from Vocational Rehabilitation. He has remained sober for nine more months and the antidepressant is being gradually decreased (15 mg b.i.d.), and hopefully will be discontinued in three months. He has not been able to find a job (due to the poor economy of the coal market); however, social interaction has improved with rare bouts of anxiety and depression.

\section{Discussion}

The case histories illustrate that MAOI's can be useful in the treatment of certain patients with depression. The patients who respond to MAOI appear to have certain features which distinguish them from the tricyclic responders:

A) Age - younger, 20-50 years

B) Sex-usually female

C) Onset-gradual with no antecedent factors

D) Personality-described as "obsessional, demanding and hysterical"

E) Symptoms - usually "panic attacks" with feelings of anxiety; hyperventilation syndrome; somatic complaints with ANS disturbance as tachycardia, increasing perspiration; phobias (e.g., agoraphobia, social phobias); depersonalization episodes associated with marked anxiety

F) Psychological testing-MMPI scores indicate high score on anxiety, depression, hysteria and obsessionality; mood is often described as dysphoric and personality as histrionic

The response to the MAOI is usually seen within one to two weeks. If no response is noted within four weeks with adequate doses, the drug is probably unlikely to be beneficial and should be discontinued. The initial dose of Parnate is $10 \mathrm{mg}$ daily and is increased gradually to an optimum dose of $20-60 \mathrm{mg}$ /day in two doses. Nardil (phenelzine is initiated in the dose of $15 \mathrm{mg}$ daily, and is increased by $15 \mathrm{mg}$ every two to three days until an optimum does of $60-90 \mathrm{mg} /$ day in two doses is reached. Late evening and bedtime doses may cause insomnia. In such cases we would suggest that the drug be given at 10AM and IPM. The duration of treatment is from six to nine months, following which the drug 
should be gradually decreased. Side effects are mild and self-limited, and relate to the autonomic nervous system [e.g., tachycardia, postural hypotension (dose-related), mydriasis, dry mouth, constipation, impotence, etc.]. Hypertensive episodes may result from interaction with tyramine-containing foods and sympathomimetic drugs. If used in combination with a phenothiazine (e.g., Stelazine), side effects are said to be minimized (used as "parstelin" in U.K.; i.e., a combination of Parnate and Stelazine). Patients should be given a list of foods and drugs to be avoided to prevent side effects.

Despite the risks and drawbacks cited, the authors' clinical experience, both in U.K. and U.S., shows that the monoamine oxidase inhibitors have an important role in the treatment of chronic and severe depression, and should be the first line of treatment in patients with atypical depression, phobias, panic attacks and occasionally also in some endogenous depression.

\section{References}

Blackwell, B., \& Mabbit, L.A. Tyramine in cheese related to hypertensive crisis after monoamine oxidase inhibitors. Lancet I. $1965,938-940$.
Horwitz, D. \& Dovenberg, W. Monoamine oxidase inhibitors, tyramine and cheese. Journal of American Medical Association, 1964, 188. 1108-1110.

Paykel, E.S., \& Parker, R.R. Depressive classification and prediction of response to phenelzine. Journal of Psychiatry, 1978, $134,572-581$

Quitkin, F., Rifkin, A., \& Klein, D.F. Monoamine oxidase inhibitors: A review of antidepressant effectiveness. Archives of Genenal Psychiatry, 1979, 36, 749-760.

Rees, V... Proceedings of the Royal Society of Medicine, 1972, $65,813$.

Stockley, I.H. Monoamine oxidase inhibitors, part I - interactions with sympathomimetic amines. The Pharmaceutical Journal, June 1973.

All correspondence or requests for reprints should be directed to: M. K. Hasan, M.D., Division of Behavioral Sciences \& Psychiatry, 306 Stanaford Road, Beckley, West Virginia 25801.

This project was funded in part under an agreement with the West Virginia Department of Health. - 